\title{
"Firma de Poesia": o projeto poético de Haroldo de Campos
}

\author{
Diana Junkes Martha Toneto (UNAERP)
}

\begin{abstract}
RESUMO: A discussão que aqui se propõe volta-se para o estudo da obra de Haroldo de Campos a partir da perspectiva sincrônica de abordagem da história literária que norteou suas atividades. Nesse sentido, poder-se-ia delinear um projeto haroldiano de poesia, cuja visão de modernidade orienta tanto a ruptura de vanguarda quanto a reinvenção do cânone, invariantes de um trabalho ao qual o poeta incorpora distintas dicções, desde o concretismo dos anos iniciais até os diálogos com textos bíblicos e com a ciência, percebido nos últimos poemas. Essas instâncias, todavia, parecem não significar apenas uma sucessão de fases, mas sim o aprofundamento de um modo de conceber a poesia que tem início na década de 1950 e marca-se pela busca da materialidade poética e pela invenção, ao mesmo tempo que revelam a dívida do poeta para com a tradição literária, sobretudo a brasileira.
\end{abstract}

PALAVRAS-CHAVE: Haroldo de Campos; projeto poético; poética sincrônica; tradição; modernidade.

ABSTRACT: The aim of this article concerns to the Haroldo de Campos 's work analyses, since the synchronic perspective of literary approach. In this sense, it is possible to define a haroldian poetry project which modernity vision orientates the vanguard rupture and the canon reinvention, invariants of a work that coordinate different accents, since the concretism of the first years until the biblical dialogues and science presented in the last texts. These instances, although, seems not a succession of degrees, but more than this, reveals a conception of poetry marked by the search of the poetic word materiality and the inventiveness, at the same time that shows up a sense of poet's gratitude to the literary tradition, specially the Brazilian one.

KEYWORDS: Haroldo de Campos; poetry project; synchronic poetics; tradition; modernity.

\section{A Firma de Poesia}

Conta-se que certa vez Oswald de Andrade deu a Augusto e a Haroldo de Campos um livro com dedicatória aproximadamente assim: "Para os Irmãos Campos, Firma de Poesia”. Essa dedicatória poderia ser explicada, certamente, a partir de muitas e rememoráveis histórias. Interesso-me aqui, especificamente, pela "Firma de Poesia" e 
pelo que essa colocação implica em termos do fazer poético de Haroldo de Campos. Segundo o Dicionário Novo Aurélio, assim pode-se definir firma:

[Dev. de firmar]. S.f. 1. Assinatura por extenso ou abreviada, manuscrita ou gravada. 2. Ponto de apoio. 3. Estabelecimento comercial ou industrial [...]. 4. JurNome us. pelo comerciante ou industrial (pessoa natural ou jurídica) no exercício de suas atividades; razão social. (FERREIRA, 1999, p. 908).

A definição sugere a polissemia do termo e constitui-se em bom ponto de partida para a compreensão do fazer poético calcado na modernidade desenvolvido pelos poetas concretos paulistas. Se entendida a firma como assinatura, a assinatura da/na poesia, no caso aqui apresentado, pode-se pensar na própria importância da poesia dos irmãos Campos, responsáveis por uma nova assinatura na poesia brasileira, por meio da retomada de muitas das idéias do próprio Oswald. (CAMPOS, 1992, p.231-256). Uma assinatura que se iria inscrever na história da literatura brasileira. Se entendida como ponto de apoio, a firma de poesia revela a própria palavra poética como sustentação da criação via linguagem.

São, entretanto, as duas últimas acepções que parecem melhor servir à compreensão do trabalho inaugurado pelos poetas concretos em meados da década de 1950: a caracterização da firma como estabelecimento comercial, ou, melhor ainda, para o caso criativo de Haroldo e Augusto, estabelecimento industrial, sugere a associação dos trabalhos poéticos dos dois irmãos a um fazer artístico criterioso, um ofício de fato, que visa a uma produção poética.

Esse "estabelecimento poético-industrial" certamente deveria contar com uma razão social - nome ou assinatura do estabelecimento, ou, simplesmente, a razão de ser da poesia, sua função social em termos de revigoração da linguagem e compromisso com a língua, conforme os termos de Eliot. Tal compromisso desdobra-se, evidentemente, na multiplicidade de vertentes criativas em que atuaram (e atua, ainda, Augusto de Campos): da poesia à crítica, passando pela tradução.

Segundo essa perspectiva, o fazer poético de Augusto e de Haroldo assumiria sério compromisso com a palavra poética em termos "sócio-criativos". A novidade e a invenção, bem como a consideração da antropofagia são cruciais para entender seus 
preceitos criativos. A meu ver, entretanto, há mais do que novidade e invenção nos projetos poéticos de ambos, estendidos para além das bordas da Poesia Concreta. Sobretudo, há mais reinvenção e historicidade no projeto de Haroldo de Campos do que se possa supor a partir de uma leitura inicial de sua obra.

Neste ensaio irei ater-me especificamente à obra de Haroldo de Campos. A breve discussão apresentada a seguir ressalta uma possibilidade de estudos críticos acerca de sua obra a partir da perspectiva sincrônica de abordagem da história literária, norteadora de suas atividades. Nesse sentido, pode-se delinear uma leitura da obra haroldiana, cuja visão poética se orienta tanto pela ruptura de vanguarda quanto pela reinvenção do cânone, invariantes de um trabalho ao qual o poeta incorpora distintas dicções, desde o concretismo dos anos iniciais até os diálogos com textos bíblicos e com a ciência, percebido nos últimos poemas, entre outros traços herdados da tradição. Essas instâncias, todavia, parecem não significar apenas uma sucessão de fases, mas sim o aprofundamento de um modo de conceber a poesia que tem início na década de 1950 e marca-se pela busca da materialidade poética e pela invenção, inclusive, e talvez principalmente, na tradição literária. A tensão entre espalhar a novidade e impedir a tradição de cristalizar-se engendra a construção do projeto haroldiano.

\section{O poeta concreto e a tradição}

Desde os primeiros poemas observa-se, em Haroldo de Campos, um profundo respeito e uma "dívida", se é que se pode dizer assim, para com a tradição. A inserção dos textos passados em sua obra dá a ela um caráter de palimpsesto e exige do leitor leitura atenta e muita erudição, posto não serem poucas as citações, as paráfrases e as mais variadas formas de referência ao cânone que surgem em sua obra. Segundo o próprio poeta, este modo de incluir a tradição em seus textos pode ser definido como perspectiva sincrônica da abordagem literária, de acordo com a qual a constituição do presente dá-se em função das escolhas/ reconstruções do passado (CAMPOS, 1997, p.243). Em outras palavras: o retorno ao passado (sincronia) em termos de escolha/ construção de um paideuma, é marcado por uma postura construída no presente que seleciona da série literária aquilo que deve permanecer para possibilitar a construção de uma história plurissignificativa, capaz de tornar contemporâneos "Safo e Bashô, Dante e 
Camões, Sá de Miranda e Fernando Pessoa, Hölderlin e Celan, Góngora e Mallarmé”, poetas concretos porque a palavra em suas obras surge em função poética, palpável e plasticizada, iconizada. (ibid, p.268-269). Para além das particularizações impostas pela história literária diacrônica, o paradigma haroldiano é inclusor sempre, desde que se considerem a inventividade e a ruptura como critério de inclusão.

Há, ainda, outro aspecto importante a ser destacado no que concerne ao trabalho criativo de Haroldo de Campos. Trata-se de considerar todas as vertentes de sua obra (poesia, tradução e crítica) como uma tríade essencial ou, mais do que isso, como unidade orientada pela preocupação com a concreção sígnica. Nesse sentido, é sempre importante lembrar as palavras de João Alexandre Barbosa a esse respeito: "Poesia, tradução e crítica para mim, [...] não são senãopersonae de um criador empenhado em buscar limites (ou as ilimitações?) de uma inserção na história de seu tempo, quer dizer, na linguagem de seu tempo. História e linguagem: passagens" (BARBOSA, 1979, p.20). Destarte, quando se pensa em projeto poético de Haroldo de Campos deve-se pensar nas três vertentes de sua atuação em termos de trabalho com a linguagem e devese pensar que tanto a crítica quanto a tradução são subproduto de uma poética em ação, cuja engrenagem é o pensamento poético e sua preocupação em fazer convergir passado e futuro na linguagem presente, definindo, pois, uma poética da agoridade (CAMPOS, 1996, p.16; CAMPOS, 1997, p.269).

A inserção do poeta na linguagem do seu tempo pode ser compreendida tanto do ponto de vista de sua relação com o cânone universal, quanto do ponto de vista de sua relação com a literatura brasileira; nesse sentido, nota-se a tentativa de estabelecimento de uma busca de suas próprias origens por meio da criação de precursores brasileiros, criação esta que deve aqui ser entendida em termos borgianos (BORGES, 1982, p.226228). O projeto poético de Haroldo de Campos pode, desse modo, ser mais bem precisado quando se assume a importância dos diálogos com a tradição em sua obra, sobretudo os diálogos com a nossa tradição, responsáveis, provavelmente, pela brasilidade operante na recriação que o poeta faz do cânone universal e no modo como se relaciona com o mundo propriamente dito. Apenas a título de exemplo, veja-se o poema abaixo, publicado em Crisantempo (1998, p.89-93): 


\section{MENINOS EU VI}

vi oswald de andrade

o pai antropófago em 49

reclinado numa cadeira de balanço

[...]

vi ezra pound em 59

na via mameli em rapallo

(tuesday four pm ore sedici)

$[\ldots]$

vi roman jakobson en la jolla

califórnia ano 66

(a seu lado kristina pomorska loura cabeça altiva)

$[\ldots]$

$[\ldots]$

vi tudo isso e muitas outras coisas

$[\ldots]$

No poema acima, as referências dizem respeito, aparentemente, apenas às várias experiências do poeta, aos amigos que fez e às influências recebidas em sua obra. Tudo isso fica claro pela leitura do fragmento, porém, há mais do que referências; há, sim, a citação direta de Gonçalves Dias e de seu I-Juca-Pirama (2008, p.1149). Para contar o heroísmo do tupi que foi digno de ser morto pelos timbiras, o velho timbira que tudo presenciou aciona a memória e narra, aos jovens índios de sua tribo, o que viu, assim:

$\mathrm{X}$

Um velho Timbira, coberto de glória Guardou a memória Do moço guerreiro, do velho Tupi E à noite, nas tabas, se alguém duvidava Do que ele contava

Dizia prudente: - "Meninos, eu vi!"

Eu vi o brioso no largo terreiro

Cantar prisioneiro

Seu canto de morte, que nunca esqueci: Valente, como era, chorou sem ter pejo; Parece que vejo,

Que o tenho nest'hora diante de mi 
Haroldo de Campos, em seu poema, recria o papel do aedo gonçalvino e conta o que viu; o que diferencia ambos, entretanto, é o fato de o eu-poético haroldiano narrar os próprios feitos do poeta e aqui há, então, uma mistura; o épico não remete tanto à Ilíada ou à Eneida como em Gonçalves Dias (FRANCHETTI, 2008, p. 1113), mas à Odisséia. Como Ulisses, o poeta de "Meninos eu vi", falará de seus feitos e, sobretudo, de suas viagens. De fato, as viagens são tema constante na obra de Haroldo, também caracterizada grandemente pelo épico, configurando-se ambos como suas predileções, ou, mais ainda, suas obsessões. Outro aspecto que merece ser destacado aqui é a parábola haroldiana, pois "Haroldo é o personagem central de suas criações" (VIEIRA, 2006, p.6).

Severo Sarduy percebe cada texto de Haroldo de Campos como parábola da sua escritura, um mapa do Brasil (SARDUY, 1979, p. 123, 125). Em cada texto, poema, transcriação e estudo crítico, a historicidade da obra do poeta configura-se como parábola pessoal e nessa escritura em certa medida confessional (Meninos eu vi) o poeta estabelece uma associação entre sua palavra e os diálogos com a tradição literária, atribuindo supremacia às referências brasileiras. Em certa medida, poderíamos dizer, portanto, que a obra de Haroldo de Campos é confessional: retoma a tradição e seus próprios textos de modo que cada texto seu pode ser visto como acervo dos anteriores; ao mesmo tempo, esse acervo é organizado por um "curador" que tem seu fazer determinado pela literatura e pela cultura brasileiras, especialmente quando transcria os textos da mais alta tradição literária. Um exemplo dessa atitude pode ser extraído de comentário feito pelo poeta:

Aí vou pôr algumas traduções especiais, uma delas uma tradução de Horácio, de uma ode de Horácio, de uma ode famosa que começa assim: "pérsicos odi, puer, apparatus” [...]. A minha tradução retoma Horácio por via de Noel Rosa:

Garçom, faça o favor, nada de luxos persas. Não me venha com estes 
enfeites de tília.

Rosas? Não quero rosas

se alguma ainda esquiva.

$[\ldots]$

Este tipo de trabalho é um modo de fazer o novo, de fazer Horácio cantar Noel Rosa, por que não? (CAMPOS, 1996, p.24,25).

Ensina Antonio Candido que a literatura afina a nossa visão de mundo, orquestra-a; quer percebamos ou não, ela influencia a nossa forma de conceber o entorno (2004, p.170); claro está, portanto, que Haroldo de Campos não poderia furtar-se aos determinismos da literatura e da cultura brasileiras; por outro lado, como não há fronteiras em termos de arte, já que a obra de arte é aberta (CAMPOS, 1955), a herança universal mescla-se ao olhar marcado pela nossa cultura para definir matizes impressionantes; uma obra única e alicerçada pela vanguarda, mas que tem, nos andaimes da tradição, sua sustentação.

Dada a sua postura vanguardista e a preocupação com a construção do poema como objeto de linguagem, preocupação esta orientada pela função poética jakobsoniana, Haroldo de Campos é normalmente visto, dentro do escopo da literatura brasileira, como herdeiro de João Cabral de Melo Neto; dada a preocupação com a devoração cultural crítica da tradição, estabelece-se um linha sucessória OswaldHaroldo. Todavia, se a antropofagia oswaldiana e o rigor cabralino são invariantes de seu trabalho, as heranças drummondianas e rosianas, a precisão euclidiana, o lirismo de Bandeira, os signos intensos de Sousândrade e muitas outras referências da nossa literatura e de nossa cultura marcam também a obra haroldiana e surgem ora como estudos críticos, ora como aportes da prática tradutória, mas, fundamentalmente, incorporadas aos próprios poemas. Um exemplo muito instigante desses aportes, ou ainda, desses portos para onde convergem os navios criativos de Haroldo, é o poema $A$ Máquina do Mundo Repensada. Nesse poema, o último publicado pelo poeta, a literatura brasileira surge em refrações prismáticas, fundando uma cosmogonia que começa com ares drummondianos e termina retomando o nonadarosiano. 
Não se pode deixar de mencionar neste ponto que o poeta faz a leitura da tradição literária e da história da maneira como faz porque sua leitura é historicamente datada, assim como são historicamente datados os textos com os quais dialoga. À sincronia haroldiana, construída no limiar do século XXI, é preciso acrescer a diacronia dos processos históricos, inclusive aquela que ele mesmo vivencia; esse processo sincrônico-diacrônico permite situar o fazer poético haroldiano (incluem-se neste fazer a tradução e a crítica) como um catalisador de múltiplas experiências culturais e históricas unificadas pela arte poética: poesia, catarse (BARBOSA, 1979, p.18).

O movimento de leitura sincrônico-diacrônico é modelar para a compreensão do direito (humano) à literatura a que todos temos nos moldes suscitados por Antonio Candido no ensaio $O$ direito à literatura (2004, p. 169-192), à medida que incorpora tanto a literariedade das obras, afirmando-as como direito universal, porque dão forma aos sentimentos e nos humanizam quanto se revela como instrumento de compreensão do mundo em que vivemos e, no caso específico da obra haroldiana, da nossa sociedade. A obra de Haroldo toma os clássicos em posição dialógica e é a partir desse diálogo que situa a literatura brasileira e nossa sociedade. Tal movimento dá, ao poeta, oportunidade de inserir-se na linguagem de seu tempo e dá, principalmente, condições para que ele, por meio de sua palavra, pense a nossa sociedade, cumprindo, dessa forma, a razão (social) de ser da firma poética que estabelece com seu ofício de poeta.

A historicidade do projeto poético de Haroldo de Campos não só cumpre importante papel dentro de nossa cultura, pois antropofagicamente revitaliza a literariedade dos textos universais, como também (re)significa a própria experiência de leitura do cânone brasileiro. Para dar conta disso, apóia-se no dialogismo que os clássicos, com sua vocação para o futuro, legaram-nos (BRANDÃO, 1992, p.42). Na cosmogonia criativa de Haroldo de Campos, constelações históricas reluzem por meio da literatura e da informação estética que ela veicula e, por isso, pela potencial capacidade de organização de nosso mundo interior que possibilita e por permitir, também, que na esteira do poeta repensemos nossa relação com a sociedade brasileira, tais constelações históricas significam concretamente, materializadas pela palavra poética haroldiana que não se restringe apenas a seus poemas e faz convergir o passado 
(tradição literária) e a projeção futura (alavancada pelo discurso de vanguarda) para o presente, grande mediador transtemporal do pensamento poético haroldiano.

O pensamento (poético) de Haroldo de Campos ora se aproxima da tradição, inclusive pela forma adotada nos poemas, como em Lamento sobre o lago Nemi, de 1950, republicado em "Xadrez de Estrelas" (1976), ou o já citado poema A Máquina do Mundo Repensada (2000); ora corrompe essa forma e reivindica para a tradição um lugar de (re)significação das experimentações da linguagem fundadas na modernidade por Mallarmé e Joyce, por exemplo. É o caso de ô âmago do ômega, de 1955-1956, também republicado em "Xadrez de Estrelas" (1976) e de Galáxias, escrito entre 19631976, poemas em que se verificam citações de distintos precursores do poeta.

É interessante comentar que em Galáxias, Haroldo, o vanguardista, evoca ninguém menos do que o parnasiano Bilac. "Ora, direis, ouvir galáxias" é o nome do texto elaborado por Haroldo de Campos acerca de seu poema (CAMPOS, 2004, p.119). Do Xadrez de Estrelas que nomeia antologia poética de Haroldo de Campos, retomando Padre Antonio Vieira, a Galáxias, percebe-se nos poemas de Haroldo um eu-poético viajor que no périplo do poema resgata companheiros de viagem, devolve-lhes à vida, não como esta fora, mas como (im)possibilidade de existência no presente assegura que as constelações poéticas permaneçam reluzindo mesmo após a morte das estrelas da tradição que as originaram.

\section{Para ler o projeto poético de Haroldo de Campos: caminhos possíveis}

Um estudo do projeto poético de Haroldo de Campos poderia, pois, ser desmembrado em três partes correlatas. Em primeiro lugar, seria importante identificar e discutir diálogos com a literatura brasileira, estabelecendo quais as invariantes das escolhas do poeta no que concerne ao nosso cânone, ou seja, qual literatura brasileira é resgata por ele. Cabe destacar que, pelo estabelecimento dessas intertextualidades, certamente se estará ampliando a perspectiva sincrônica defendida pelo próprio poeta, pois que a ela serão incorporados, inevitavelmente, fatores como o contexto de produção/recepção das obras referidas, uma vez que estes engendram tanto significados quanto significantes (tão valorizados pela visada vanguardista que marca a obra haroldiana). 
Em segundo lugar, ao mediar essas interfaces entre a obra de Haroldo de Campos e o estudo dos autores e obras brasileiros que ele lê permitiria a análise de suas produções sob ampla perspectiva, destacando-se tanto sua potencial característica para apreender e conhecer a realidade quanto sua potencial força para transformá-la e criá-la, porque como diz Campos deve-se pensar que "[a] poesia engloba uma prática e uma história" (CAMPOS, 1996, p.14). Diante disso, fica claro porque tanto a preocupação com a novidade quanto àquela referente à manutenção da tradição são cruciais para a compreensão do projeto poético de Haroldo de Campos.

Em terceiro lugar, seria interessante averiguar em que medida a presença da história da literatura brasileira que se ergue do seu fazer criativo é crucial para o poeta Haroldo de Campos enquanto instrumento construtivo do mesmo. Uma vez que os diálogos com a tradição são marca da obra haroldiana, resta saber se a literatura brasileira tem peso igual ou maior que o cânone universal em termos da construção da obra do poeta. Seria interessante estimar, por fim, em que medida Haroldo de Campos lê a tradição literária como um contínuo indistinto, "tradição literária", em que tanto o cânone universal como o brasileiro têm papéis iguais, ou se a brasilidade de sua leitura o faz preponderar a nossa tradição e, a partir dos nossos referenciais, é que ele irá valorizar determinado cânone universal.

Como os fragmentos coloridos de um caleidoscópio dotado de dinamismo próprio, a tradição se estilhaça na obra haroldiana para ser, ali mesmo, em seu escopo, restaurada em suas máximas potencialidades, segundo o olhar que lhe atribui um poeta cujo discurso marca-se pela vanguarda, pela antropofagia, pela urgência do "make it new" poundiano e, simultaneamente, devota profunda gratidão aos clássicos.

O projeto poético haroldiano, calcado na construção de um paideuma que é articulado por sua poética sincrônica rompe a linearidade do pensamento positivista com que é tratada a História Literária na maioria das vezes, desse modo, a tradição incorpora-se à obra de Haroldo de Campos em termos sintáticos e semânticos e se mescla ao presente que a restaura, re-inventa, livra-a do inconformismo (BENJAMIM, 1996, p.224). 
O retorno de Haroldo de Campos à tradição assume estatuto de travessia; não só o poeta fala de suas viagens pela voz de seus diferentes eu-poemáticos, aedos de seus poemas e transcriações, como a busca e a invenção de seus precursores constituem-se em etapas de seu percurso de volta às origens. Mas para conduzir este Odisseu a Ítaca merecida é preciso lançar novos alísios à sua poética sincrônica, talvez entendendo que o reconhecimento e a gratidão orientem a necessidade de fazer os textos da tradição sobreviverem; a sobrevivência destes garantiria a escritura da parábola haroldiana, a sobrevivência do próprio poeta e de seu canto órfico.

É porque vai ao Hades que Haroldo (Odisseu-Orfeu) reconhece o que herdou; revê os companheiros, indaga pelo caminho da volta e se percebe disposto a ultrapassar o signo para ouvir o canto arriscado das sereias da tradição ou das sirenes da urbe moderna, como diz em seuFinismundo: a última viagem (1990). É porque vai ao Hades que tenta resgatar e trazer à luz os companheiros, como ensina Donaldo Schüler (1997). Entretanto, diferentemente do Orfeu do mito, Haroldo não volta os olhos, sabe que os companheiros o acompanham; é Odisseu demais para prender-se às imagens dos mortos, precisa viver o luto por eles fazendo-os viver como espectros em si mesmo, em sua palavra marcada de gratidão (MARGEL, 2000; SISCAR, 2000).

Por fim, é porque vai ao passado com os olhos postos no horizonte que o futuro acena-lhe, que o poeta evita seu próprio esfacelamento; costura vozes e cantos, orquestra-os ao seu próprio dizer Ur-poético, presentificado na palavra plasticizada que permeia a materialidade dos signos moventes no universo que fundou. Haroldo sempre soube que viver é mesmo perigoso se a vida não for compreendida a partir da travessia entre o ontem e o amanhã. Para o poeta, viver era simplesmente preciso como risco, nada feito no nada, presente absoluto ou acaso indomável: um lance de $\infty$. 


\section{Referências Bibliográficas}

BARBOSA, J.A. Um Cosmonauta do Significante: Navegar é Preciso. In: Signantia: Quasi Coelum Signância: Quase Céu. São Paulo: Ed. Perspectiva, 1979, p.11-24. BENJAMIM, W. Magia e Técnica, Arte e Política. In: Obras Escolhidas. São Paulo: Ed. Brasiliense, 1996. Vol. 1, p. 222-234.

BORGES, J.L. Kafka y sus Precursores, In: Prosa Completa. Buenos Aires: Bruguera, 1982, vol.2, p 226-228.

BRANDÃO, J. L. Primórdios do Épico: A Ilíada. In: APPEL, M. B.; GOETTEMS, M.B. (org) As Formas do Épico. Porto Alegre: Ed. Movimento/ UFRGS, 1992.

CANDIDO, A. O Direito à Literatura. In: Vários Escritos. São Paulo: Duas Cidades, 2004, p. 169-192.

CAMPOS, H. A Obra de Arte Aberta (1955) In: CAMPOS, H., CAMPOS, A. e PIGNATARI, D. Teoria da Poesia Concreta. São Paulo: Ed. Invenção, 1975, p. 30-33. . Xadrez de Estrelas. São Paulo: Ed. Perspectiva, 1976. . Signantia Quasi Coelum, Signância Quase Céu. São Paulo: Ed. Perspectiva, 1979.

Finismundo: A Última Viagem. Ouro Preto: Tipografia do Fundo de Ouro Preto, 1990.

Da Razão Antropofágica: diálogo e Diferença na Cultura Brasileira.

In: Metalinguagem e Outras Metas. São Paulo: Ed. Perspectiva, 1992, p.231-256. . Sobre Finismundo: a última viagem. Rio de Janeiro: [7 Letras], 1996. Poesia e Modernidade: Da Morte do Verso à Constelação. O Poema PósUtópico. In: O Arco Íris Branco. São Paulo: Ed. Imago, 1997, p. 243-270. Crisantempo: No Espaço Curvo Nasce Um. São Paulo: Ed. Perspectiva, 1998. A Máquina do Mundo Repensada. São Paulo: Ateliê Editorial, 2000. Depoimentos de Oficina. São Paulo: Unimarco, 2002. Ora Direis, Ouvir Galáxias In: Galáxias. 4ª ed. São Paulo: Ed. 34, 2004, p. 119-123.

DIAS, G. I-Juca-Pirama. In: TEIXEIRA, I. Multiclássicos Épicos. São Paulo: Edusp/ Imprensa Oficial, 2008, p. 1131-1151.

FERREIRA, A.B. Novo Dicionário Aurélio. Rio de Janeiro: Nova Fronteira, 1999. FRANCHETTI, P. O Triunfo do Romantismo: Indianismo e Estilização Épica em Gonçalves Dias. In: In: TEIXEIRA, I. Multiclássicos Épicos. São Paulo: Edusp/ Imprensa Oficial, 2008, p. 1097-1130.

MARGEL, S. As denominações órficas da sobrevivência: Derrida e a questão do pior. In: NASCIMENTO, E.; GLENADEL, P. Em Torno de Jacques Derrida. Rio de Janeiro: [7letras], 2000, p. 203-230.

SARDUY, S. Rumo à concretude. In: CAMPOS, H. Signancia Quasi Coelum, Signância Quase Céu. São Paulo: Perspectiva, 1979, p.117-126.

SCHÜLER, D. Um lance de nadas na épica de Haroldo. Ponta Grossa: UEPG/ Museu Arquivo da Poesia Manuscrita, 1997. Col. Mapa. 
SISCAR, M. A Paixão Ingrata. In: NASCIMENTO, E.; GLENADEL, P. Em Torno de Jacques Derrida. Rio de Janeiro: [7letras], 2000, p. 160-187.

VIEIRA, T. A Odisséia de Haroldo de Campos (apresentação). In: Odisséia de Homero: fragmentos. Tradução de Haroldo de Campos. CAMPOS, I.; TÁPIA, M. (org.). São Paulo: Olavobrás, 2006, p.5,6.

TONETO, D. J. M. Convergências em A Máquina do Mundo Repensada: Poesia e Sincronia em Haroldo de Campos. Tese de doutoramento. Araraquara: UNESP/ Faculdade de Ciências e Letras, 2008. 298p. 